\title{
Treatment of patients with Covid-19 with a high dose of ulinastatin
}

\author{
HAI HUANG ${ }^{1 *}$, PING-FANG HU ${ }^{2 *}$, LIANG-LIANG SUN ${ }^{3 *}$, YI-BIN GUO ${ }^{4 *}$, QIONG WANG ${ }^{1}$, \\ ZHI-MIN LIU ${ }^{2}$, JI-ZHONG YIN ${ }^{1}$, PEI-MEI SHI ${ }^{2}$, ZONG-LI YUAN ${ }^{2}$ and WEI-FEN XIE ${ }^{2}$ \\ Departments of ${ }^{1}$ Pulmonary and Critical Care Medicine, ${ }^{2}$ Gastroenterology and ${ }^{3}$ Endocrinology, \\ Changzheng Hospital, Second Military Medical University, Shanghai 200003; ${ }^{4}$ Department of \\ Health Statistics, Second Military Medical University, Shanghai 200433, P.R. China
}

Received January 14, 2021; Accepted October 7, 2021

DOI: 10.3892/etm.2021.11044

\begin{abstract}
Currently, there are no specific therapeutic agents available for the treatment of coronavirus disease 2019 (Covid-19). The present study aimed to assess the efficacy of high-dose ulinastatin for the treatment of patients with Covid-19. A total of 12 patients hospitalized with confirmed severe acute respiratory syndrome coronavirus 2 infection were treated with a high dose of ulinastatin alongside standard care. Changes in clinical manifestations, laboratory examinations and chest images were retrospectively analyzed. A total of 10 patients with severe Covid-19 and two patients with moderate Covid-19 received ulinastatin treatment. The average age of the patients was $68.0 \pm 11.9$ years (age range, 48-87 years). In total, nine of the 12 patients $(75.0 \%)$ had one or more comorbidities. The most common symptoms on admission were fever $(8 / 12,66.7 \%)$, cough $(5 / 12,41.7 \%)$ and dyspnea $(5 / 12,41.7 \%)$. The percentage of lymphocytes was decreased in $41.7 \%$ of patients $(5 / 12)$ and $58.3 \%$ of patients (7/12) had elevated hypersensitive C-reactive protein (CRP) levels (mean, 49.70 $\pm 77.70 \mathrm{mg} / \mathrm{l}$ ). The white blood cell levels and the percentage of lymphocytes returned to normal in all of the patients, and CRP was significantly decreased and returned to normal in $83.3 \%$ of patients $(10 / 12$; mean, $6.87 \pm 6.63 \mathrm{mg} / \mathrm{l})$ on day 7 after ulinastatin treatment. Clinical symptoms were relieved synchronously. The peripheral oxygen saturation improved and $66.7 \%$ of the patients $(8 / 12)$ did not require further oxygen therapy 7 days after ulinastatin treatment. No patients required intensive care unit admission or mechanical ventilation. All patients revealed different degrees of absorption of pulmonary lesions after treatment. Compared with the standard care group, ulinastatin treatment
\end{abstract}

Correspondence to: Professor Wei-Fen Xie, Department of Gastroenterology, Changzheng Hospital, Second Military Medical University, 415 Fengyang Road, Shanghai 200003, P.R. China

E-mail:weifenxie@medmail.com.cn

${ }^{*}$ Contributed equally

Key words: coronavirus disease 2019, protease inhibitor, ulinastatin, inflammation, cytokine storm significantly prevented illness deterioration. In conclusion, these preliminary data revealed that high-dose ulinastatin treatment was safe and exhibited a potential beneficial effect for patients with Covid-19.

\section{Introduction}

Coronavirus disease 2019 (Covid-19) is a respiratory tract infection caused by severe acute respiratory syndrome coronavirus 2 (SARS-CoV-2) (1). Covid-19 has now become a worldwide pandemic, which poses a global health emergency (2). While the majority of patients with Covid-19 have mild to moderate symptoms, $\sim 14 \%$ of patients may progress to severe pneumonia and exhibit considerable mortality worldwide (3). To date, 11 vaccines for SARS-CoV-2 have been approved by emergency use authorization worldwide (4); however, mutations in SARS-CoV-2 have emerged worldwide, which poses a significant challenge to the vaccines (5). Despite several agents, including bamlanivimab, remdesivir, baricitinib and tocilizumab, being recommended for use in certain patients with Covid-19, their efficacy has been reported to be unsatisfactory $(4,6)$; therefore, effective therapeutic agents for severe Covid-19 are still urgently required.

The immunological characteristics of patients with severe Covid-19 include markedly elevated serum levels of proinflammatory cytokines, including interleukin (IL)-6, tumor necrosis factor- $\alpha$ and IL-1 $\beta$, characterized as a cytokine storm $(7,8)$. The cytokine storm has been hypothesized to serve a critical role in Covid-19 progression, deterioration and even death (8). Strategies to dampen inflammatory responses have therefore been proposed (9). Nafamostat, which is a serine protease inhibitor, has been reported to effectively inhibit Middle East respiratory syndrome coronavirus $\mathrm{S}$ protein-initiated membrane fusion (10). Recently, Hoffmann et al (11) reported that SARS-CoV-2 infection depended on the host cell factors ACE2 and TMPRSS2, which could be blocked by the clinically used protease inhibitors camostat mesylate and E-64d. In addition, protease inhibitors have been suggested as a promising therapeutic option to block the virus from entering host cells and to prevent future pandemics at the very beginning (12).

Ulinastatin is a glycoprotein that is extracted and purified from fresh human urine. Ulinastatin can inhibit the activity of various proteolytic enzymes and has been widely used for the 
treatment of acute pancreatitis (13). Moreover, ulinastatin has been demonstrated to be an important anti-inflammatory and antioxidative agent, and has been clinically used as a potential treatment for circulatory shock, severe sepsis and acute respiratory distress syndrome (14-16). As a protease inhibitor, whether ulinastatin has beneficial effects on Covid-19 is unknown to date. The present study retrospectively observed the efficacy of high-dose ulinastatin to explore an effective therapeutic strategy for patients with Covid-19.

\section{Patients and methods}

Patients and ulinastatin administration. The present study was conducted at the Optical Valley Branch of Maternal and Child Hospital of Hubei Province (Wuhan, China), which was designated for treating patients with Covid-19 aged $>14$ years, between February 19, 2020 and April 5, 2020. Electronic medical records of the patients hospitalized due to Covid-19 were delivered to Changzheng hospital (Shanghai, China). The final follow-up date was April 30, 2020. All patients were diagnosed with Covid-19 according to the guidelines for the Diagnosis and Treatment of Covid-19 issued by the National Health Commission of China (version 7.0) (17). A total of 15 patients treated with standard care, including supplement oxygen, antiviral agents and antibiotics according to the Chinese guideline for the management of Covid-19 (17) and 12 consecutive patients treated with ulinastatin (Techpool Bio-Pharma Co., Ltd.) in addition to standard care were enrolled for analysis. Ulinastatin was diluted with $50 \mathrm{ml}$ normal saline and administered via intravenous infusion. The infusion time was within $30 \mathrm{~min}$. The initial dose of ulinastatin was $1,000,000$ IU every $8 \mathrm{~h}$ and tapered down to 500,000 IU every $8 \mathrm{~h}$ after 4-7 days. The total course of ulinastatin administration was $~ 10$ days, depending on the overall status of the patients. The present study was approved by the Ethics Committee of Shanghai Changzheng Hospital and Optical Valley Branch of Maternal and Child Hospital of Hubei Province [approval no. (FYGG(L)-2020-028)].

Disease severity classification. The illness severity of Covid-19 was assessed in accordance with guidelines issued by the National Health Commission of China (version 7.0) (17). Briefly, moderate cases were defined as patients with clinical symptoms and signs of pneumonia based on CT imaging. Patients with any of the following conditions were considered severe cases: i) Respiratory distress, respiratory rate (RR) $\geq 30$ beats/min; ii) oxygen saturation $\left(\mathrm{SaO}_{2}\right)$ level $<93 \%$ while breathing ambient air; and iii) a ratio of the partial pressure of oxygen $\left(\mathrm{PaO}_{2}\right)$ to the fraction of inspired oxygen $\left(\mathrm{FiO}_{2}\right)$ $\left(\mathrm{PaO}_{2}: \mathrm{FiO}_{2}\right) \leq 300 \mathrm{mmHg}(1 \mathrm{mmHg}=0.133 \mathrm{kPa})$.

Data collection. Clinical information of all patients was retrieved from the hospital electronic medical record system, including electronic medical records, medication administration records, laboratory results and radiological examinations. Data were collected on patient characteristics, including age, sex, symptoms and comorbidities, including hypertension, diabetes mellitus (DM), cardio-cerebrovascular diseases (CCVDs), chronic obstructive pulmonary disease (COPD), malignancy, chronic liver diseases, chronic kidney diseases, neuropsychiatric diseases and infectious diseases. Clinical signs (body temperature, RR, concentration of oxygen inhalation and $\mathrm{SaO}_{2}$ ) were recorded daily during hospitalization. For laboratory tests, variables including white blood cell (WBC) count, lymphocyte count, hypersensitive C-reactive protein (CRP), total bilirubin (TB), alanine aminotransferase (ALT), aspartate aminotransferase (AST) and creatinine $(\mathrm{Cr})$ were obtained on admission and were monitored during hospitalization. In addition, the incidence of oxygen support requirements (ambient air, low-flow nasal cannula oxygen therapy, high-flow nasal cannula oxygen therapy, noninvasive mechanical ventilation and invasive mechanical ventilation), intensive care unit (ICU) admission, length of hospital stay, application of extracorporeal membrane oxygenation (ECMO) and continuous renal replacement therapy were recorded.

SARS-CoV-2 RNA was detected in nasal and pharyngeal swab specimens using reverse transcription-PCR. The viral nucleic acid was closely monitored during hospitalization until discharge or death. Viral nucleic acid was monitored with nasal and pharyngeal swab specimens, where the frequency of viral nucleic acid monitoring was not unified. The criteria for discharge strictly followed the guidelines issued by the National Health Commission of China (version 7.0) (17), which required two throat-swab samples obtained at least $24 \mathrm{~h}$ apart negative for SARS-CoV-2 RNA.

Statistical analysis. Data were collected into a Microsoft Excel spreadsheet (Microsoft Corporation). Continuous variables were described as the median (interquartile range) and were compared by unpaired Student's t-test between two groups, or paired Student's t-test between groups before and after ulinastatin treatment. Repeated measures ANOVA followed by Bonferroni post hoc tests was used for comparisons between three groups. Categorical variables were reported as the subject number with percentage, and $\chi^{2}$ test or Fisher's exact test was used to compare the difference in proportions. Graphs were generated using GraphPad Prism 5.0 (GraphPad Software, Inc.). All statistical procedures were performed using SPSS version 21.0 (IBM Corp.). Two-tailed $\mathrm{P}<0.05$ was considered to indicate a statistically significant difference.

\section{Results}

General characteristics of the patients receiving ulinastatin treatment. A total of 10 patients with severe Covid-19 and two patients with moderate Covid-19 received ulinastatin treatment (Table I). The average age of the patients was $68.0 \pm 11.9$ years, ranging from 48 to 87 years. Of the 12 patients, 10 were male $(83.3 \%)$ and two were female $(16.7 \%)$. The most common symptoms on admission were fever $(8 / 12,66.7 \%)$, cough $(5 / 12,41.7 \%)$ and dyspnea $(5 / 12,41.7 \%)$, followed by fatigue $(3 / 12,25 \%)$ and chest distress $(3 / 12,25 \%)$. Other symptoms, including headache, muscle ache, dizziness and anorexia were rare $(1 / 12,8.3 \%)$. Nine of 12 patients $(75.0 \%)$ had one or more comorbidities. Among them, hypertension was the most common comorbidity $(8 / 12,66.7 \%)$, followed by CCVDs $(2 / 12,16.7 \%)$, DM $(2 / 12,16.7 \%)$ and COPD $(1 / 12,8.3 \%)$.

Table II showed the results of baseline laboratory tests on admission. Two patients had an increase in WBC count, whereas 
Table I. Baseline demographics of patients receiving ulinastatin treatment.

\begin{tabular}{|c|c|c|c|c|c|c|c|}
\hline $\begin{array}{l}\text { Patient } \\
\text { no. }\end{array}$ & Sex & $\begin{array}{l}\text { Age, } \\
\text { years }\end{array}$ & Principle symptoms & Comorbidity & $\begin{array}{l}\text { Disease } \\
\text { severity }\end{array}$ & $\begin{array}{c}\text { Days of } \\
\text { admission from } \\
\text { symptom onset }\end{array}$ & $\begin{array}{l}\text { Days of initiation of } \\
\text { ulinastatin treatment } \\
\text { fromhospital } \\
\text { admission }\end{array}$ \\
\hline 1 & M & 73 & $\begin{array}{l}\text { Fever, dyspnea, } \\
\text { headache }\end{array}$ & Hypertension & Severe & 6 & 1 \\
\hline 2 & $\mathrm{~F}$ & 72 & Fever, cough & $\begin{array}{l}\text { Hypertension, } \\
\text { DM, CCVD }\end{array}$ & Severe & 2 & 10 \\
\hline 3 & $\mathrm{M}$ & 74 & Fever & COPD & Moderate & 8 & 8 \\
\hline 4 & $\mathrm{~F}$ & 87 & None & $\begin{array}{l}\text { Hypertension, } \\
\text { dementia }\end{array}$ & Moderate & 2 & 0 \\
\hline 5 & M & 55 & $\begin{array}{l}\text { Cough, muscle ache, } \\
\text { dyspnea, chest distress }\end{array}$ & Hypertension & Severe & 9 & 0 \\
\hline 6 & M & 72 & Cough, dyspnea & $\begin{array}{l}\text { Hypertension, } \\
\text { CCVD }\end{array}$ & Severe & 1 & 2 \\
\hline 7 & M & 77 & Fever, cough, dyspnea & $\begin{array}{l}\text { Hypertension, } \\
\text { DM }\end{array}$ & Severe & 4 & 6 \\
\hline 8 & M & 81 & $\begin{array}{l}\text { Fever, chest distress, } \\
\text { fatigue }\end{array}$ & Hypertension & Severe & 21 & 6 \\
\hline 9 & M & 57 & $\begin{array}{l}\text { Fever, cough, chest } \\
\text { distress, dyspnea }\end{array}$ & None & Severe & 24 & 0 \\
\hline 10 & M & 56 & Dizziness, fatigue & None & Severe & 18 & 1 \\
\hline 11 & M & 65 & Fever, fatigue, anorexia & Hypertension & Severe & 19 & 0 \\
\hline 12 & M & 48 & Fever & None & Severe & 6 & 0 \\
\hline
\end{tabular}

M, male; F, female; DM, diabetes mellitus; CCVD, cardio-cerebrovascular disease; COPD, chronic obstructive pulmonary disease.

one patient showed a decrease in WBC count in peripheralblood. The percentage of lymphocytes was decreased in $41.7 \%$ of patients $(5 / 12)$, and $58.3 \%$ of patients $(7 / 12)$ had elevated CRP levels (mean, $49.70 \pm 77.70 \mathrm{mg} / \mathrm{l}$ ). Nine patients received umifenovir, lopinavir-ritonavir or oseltamivir antiviral therapy. Two patients received antifungal treatment (voriconazole) because of coinfection. Five patients $(5 / 12,41.7 \%)$ received short-term intravenous methylprednisolone treatment.

Efficacy of ulinastatin treatment. The WBC levels and the percentage of lymphocytes returned to normal in all of the patients on day 7 after ulinastatin treatment (Fig. 1A and B). CRP decreased markedly and returned to normal in $83.3 \%$ of patients (10/12) on day 7 after treatment (Fig. 1C). Clinical symptoms were relieved synchronously in all of the patients. The peripheral $\mathrm{SaO}_{2}$ improved and $66.7 \%$ of the patients $(8 / 12$; $\mathrm{P}<0.001)$ did not need further oxygen therapy 7 days after ulinastatin treatment (Fig. 1D and E). No patients required ICU admission, mechanical ventilation, ECMO therapy or renal replacement therapy. All of the patients were discharged from the hospital, and the mean hospitalization time was 19.3 \pm 6.2 days.

All patients revealed different degrees of absorption of pulmonary lesions after treatment, according to the findings on chest imaging. Fig. 2 shows representative images of patient 5 . The chest CT scan of patient 5 showed bilateral, diffuse areas of consolidation, and the patient was then transferred to the Optical Valley Branch of Maternal and Child Hospital of
Hubei Province. The patient complained of severe dyspnea on admission, with an RR of 35 beats per minute. Ulinastatin was administered at a dose of 10,000,000 IU every $8 \mathrm{~h}$ immediately after admission, in addition to standard therapy. The dyspnea improved considerably the following day and almost disappeared in the resting state 3 days after ulinastatin treatment. The peripheral $\mathrm{SaO}_{2}$ reached $100 \%$ with low-flow nasal cannula oxygen therapy thereafter. The bedside chest X-ray on days 5 and 13 after treatment showed that the lesions were gradually absorbed (Fig. 2).

Liver and kidney function were also monitored during hospitalization. Two patients showed slightly elevated TB levels (55.4 and $25.8 \mu \mathrm{mol} / 1$, respectively; normal range, 3.4-20.5 $\mu \mathrm{mol} / \mathrm{l})$, two patients showed abnormal ALT levels (69.6 and 109.6 U/1, respectively; normal range, 0-55 U/1) and three patients showed abnormal AST levels (52.2, 51.0 and $37.2 \mathrm{U} / 1$, respectively; normal range, 5-34 U/1) on admission. These parameters returned to normal after treatment, with the exception of one patient with a slightly elevated AST level (70.4 U/1) and one patient with a slightly elevated ALT level (59.2 U/l; Fig. 3A-C).

Outcomes of patients treated with ulinastatin compared with standard care. A standard care group was formed by the random selection of 15 patients from the same hospital. There were no significant between-group differences regarding baseline demographics and clinical characteristics 


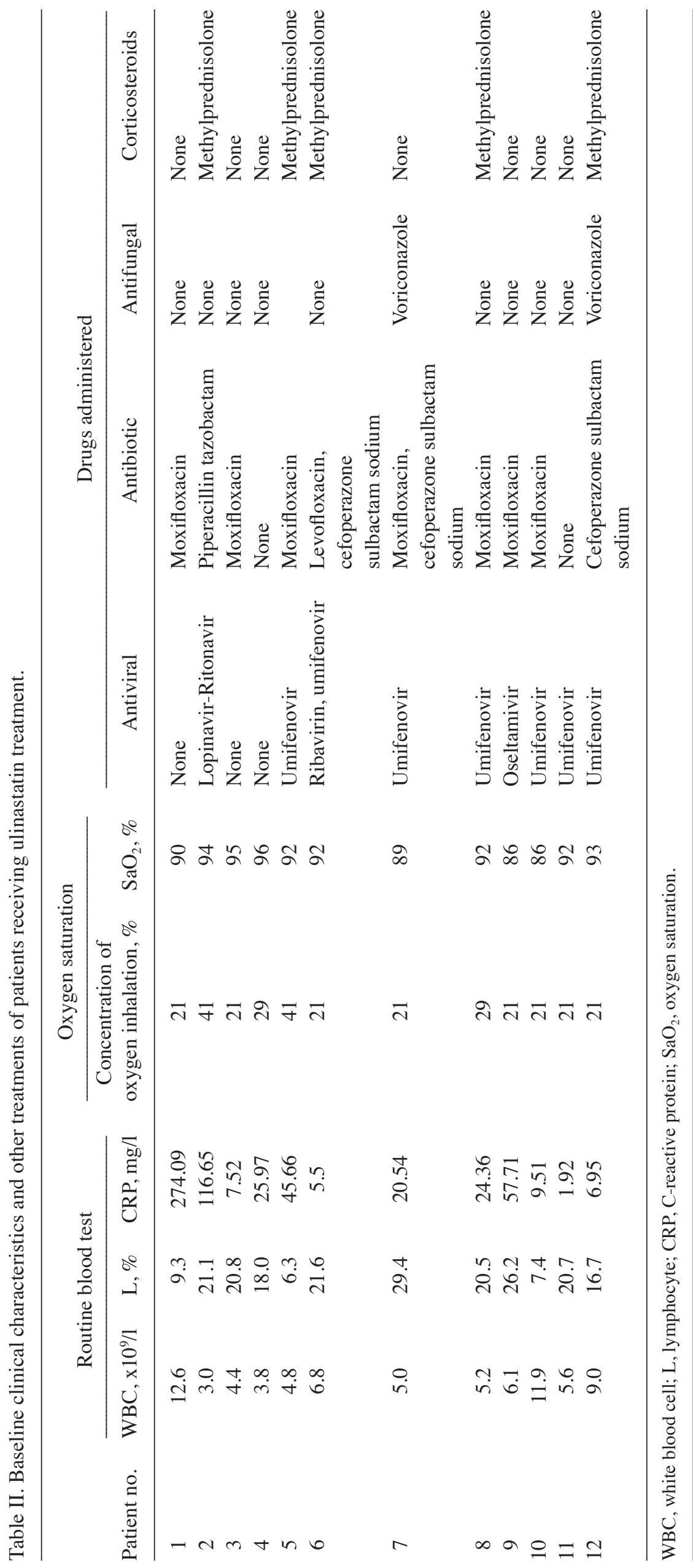



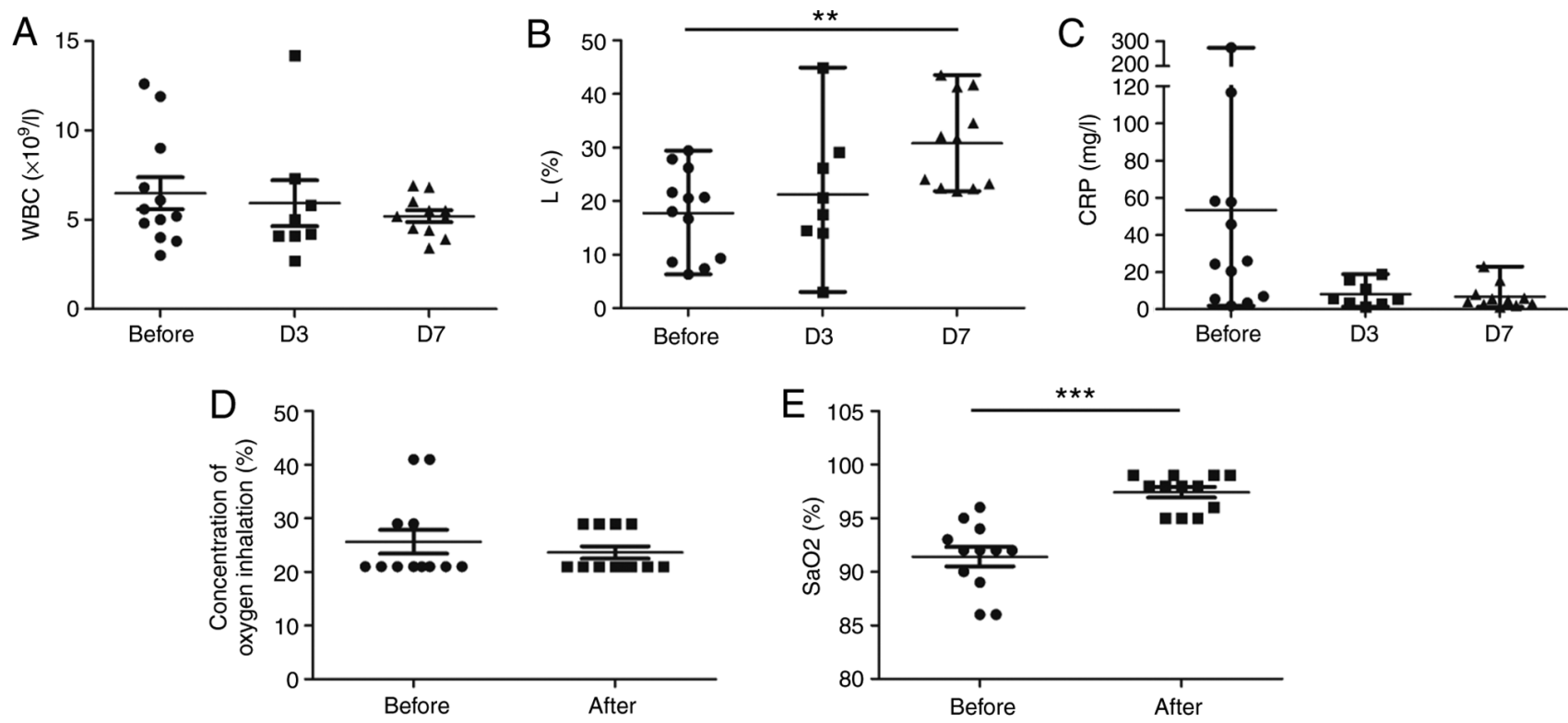

Figure 1. Dynamic changes in clinical parameters in all patients receiving ulinastatin treatment. (A) WBC count, (B) percentage of $\mathrm{L}$ and (C) hypersensitive CRP levels before ulinastatin treatment, and 3 and 7 days post-ulinastatin treatment. ${ }^{* *} \mathrm{P}<0.05$, repeated measures ANOVA. (D) Concentration of oxygen inhalation and (E) $\mathrm{SaO}_{2}$ before and after ulinastatin treatment. ${ }^{* * *} \mathrm{P}<0.001$, paired Student's t-test. WBC, white blood cell; L, lymphocyte; CRP, C-reactive protein; $\mathrm{SaO}_{2}$, oxygen saturation.

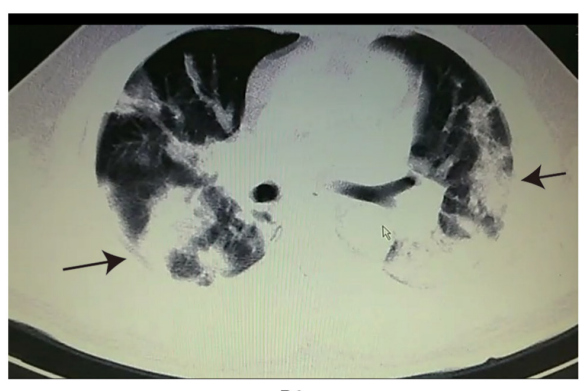

Do

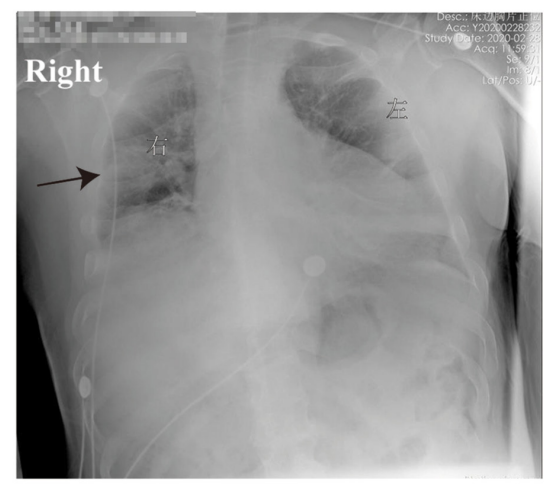

D5

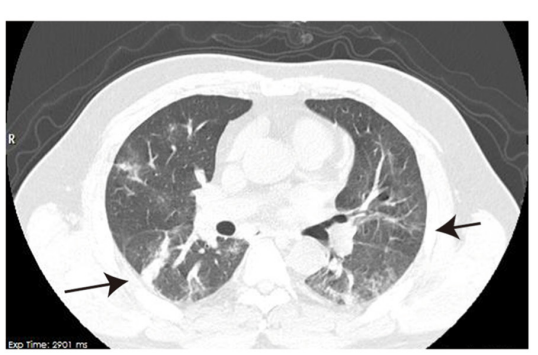

D12

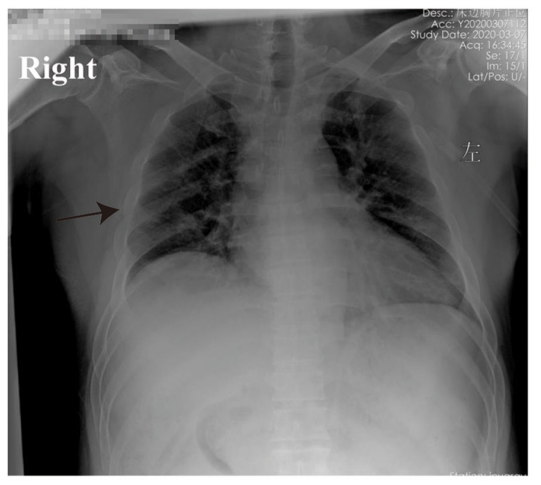

D13

Figure 2. Dynamic changes in the chest images of patient 5 showed gradual absorption of the lesions after ulinastatin treatment.

(Table III). Only one patient with moderate Covid-19 on admission progressed to severe Covid-19 during hospitalization in the ulinastatin treatment group. However, four patients with moderate Covid-19 on admission progressed to severe cases, and one patient with moderate Covid-19 and two patients with severe Covid-19 on admission deteriorated into critically severe cases during hospitalization in the standard care group $(\mathrm{P}=0.043)$. Furthermore, no mortality was observed in the ulinastatin treatment group, whereas four of 15 patients (26.7\%) died in the standard care group $(\mathrm{P}=0.106)$.

Safety. No ulinastatin infusion-related adverse events were observed. Patients with abnormal liver function on admission improved instead of deteriorating after treatment. Furthermore, the $\mathrm{Cr}$ levels were within reference range (64-104 $\mu \mathrm{mol} / \mathrm{l}$ for males and $49-90 \mu \mathrm{mol} / 1$ for females) before and after ulinastatin treatment (Fig. 3D). 

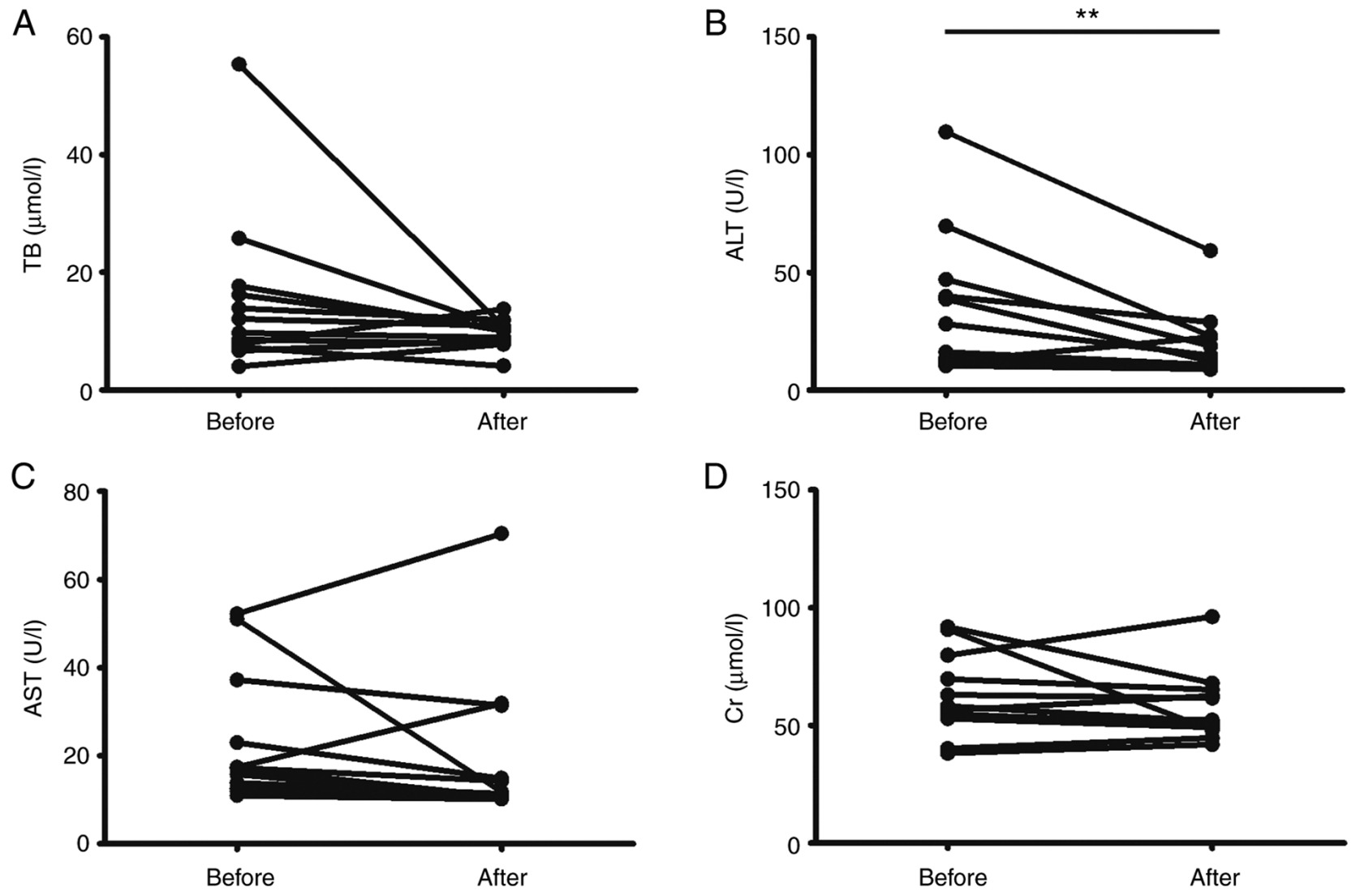

Figure 3. Values of (A) TB, (B) ALT, (C) AST and (D) Cr before and after ulinastatin treatment in 12 patients with coronavirus disease 2019. * $\mathrm{P}<0.05$, paired Student's t-test. TB, total bilirubin; ALT, alanine aminotransferase; AST, aspartate aminotransferase; Cr, creatinine.

\section{Discussion}

The present study retrospectively assessed the efficacy of ulinastatin in patients with Covid-19. This preliminary observational study revealed that high-dose ulinastatin treatment was safe and had a potential beneficial effect on patients with Covid-19, with rapid improvement of clinical symptoms, blood parameters and absorption of pulmonary lesions.

Covid-19 is spreading rapidly around the world and this unprecedented challenge demands that clinicians identify an effective and safe treatment to protect individuals at high risk (18). Remdesivir, which has been reported to exhibit potent in vitro activity against SARS-CoV-2 (19), is considered the most promising antiviral drug and has been successfully used in several case series of patients with Covid-19 (20,21). Recently, the compassionate use of remdesivir without placebo for 53 patients with severe Covid-19 was reported to have $68 \%$ efficacy (22). Notably, $23 \%$ of patients had serious adverse events, and $8 \%$ of patients discontinued remdesivir treatment prematurely. Lopinavir-ritonavir, another antiviral drug, has been shown to have no benefit for hospitalized adult patients with severe Covid-19 according to a recent open-label, individually randomized, controlled trial conducted in China (23). In addition, in this previous study lopinavir-ritonavir is also associated with serious gastrointestinal side effect, where $13.8 \%$ patients had to terminate the use of the drug earlier because of adverse events (23). Notably, older patients, especially those with comorbidities, are the most vulnerable populations to severe
Covid-19, with a significantly increased risk of deterioration and fatality (24-26); therefore, it is of utmost importance to identify effective therapeutics with high safety, probably from already clinically approved drugs. Ulinastatin is an intrinsic glycoprotein that has been widely used in clinical practice (14) and is considered an ideal candidate. A safety and tolerability study of ulinastatin in adult healthy volunteers revealed that intravenous infusion of $8,000,000 \mathrm{IU}$ ulinastatin over a $2 \mathrm{~h}$ period was associated with no severe adverse effects (27). In the present study, patients received $1,000,000 \mathrm{IU}$ ulinastatin every $8 \mathrm{~h}$ through intravenous injection, and no adverse effects were observed.

It has been reported that $\sim 14 \%$ of patients of Covid- 19 will develop into severe cases (28). Inhibition of the deterioration of the illness is of utmost importance during treatment. Potential risk factors predicting poor prognosis include older age, high Sequential Organ Failure Assessment score and d-dimer $>1 \mu \mathrm{g} / \mathrm{ml}$ (24). Therefore, the application of timely, effective and safe supportive therapies seems critical for patients with several risk factors (28). In the present study, only one patient with moderate Covid-19 progressed to a severe case while receiving ulinastatin treatment, and no mortality was observed among the patients in the ulinastatin group. By contrast, seven patients deteriorated into more severe cases during hospitalization in the standard care group ( $\mathrm{P}=0.043)$, and four of 15 patients (26.7\%) died in the standard care group.

Cytokine storms have been hypothesized to serve an essential role in the pathogenesis of Covid-19, and may be associated with disease severity and fatality $(7,8)$. Ulinastatin is an intrinsic 
Table III. Comparison of clinical features and outcomes of patients between the ulinastatin treatment group and standard care group.

\begin{tabular}{|c|c|c|c|c|}
\hline Characteristic & $\begin{array}{l}\text { Ulinastatin } \\
\text { treatment group }(n=12)\end{array}$ & $\begin{array}{l}\text { Standard care } \\
\text { group }(n=15)\end{array}$ & Statistics & P-value \\
\hline Median age, years (IQR) & $72.0(56.3,76.3)$ & $75.0(68.0,83.0)$ & $\mathrm{t}=0.970$ & $0.341^{\mathrm{a}}$ \\
\hline Male sex, $\mathrm{n}(\%)$ & $10(83.3)$ & $10(66.7)$ & & $0.408^{\mathrm{b}}$ \\
\hline \multicolumn{5}{|l|}{ Comorbidities } \\
\hline Hypertension, n (\%) & $8(66.7)$ & $6(40.0)$ & $\chi^{2}=1.899$ & $0.168^{c}$ \\
\hline $\mathrm{DM}, \mathrm{n}(\%)$ & $2(16.7)$ & $3(20.0)$ & & $1.000^{\mathrm{b}}$ \\
\hline CCVD, n $(\%)$ & $2(16.7)$ & $8(53.3)$ & & $0.107^{\mathrm{b}}$ \\
\hline COPD, n (\%) & $1(8.3)$ & $3(20.0)$ & & $0.605^{\mathrm{b}}$ \\
\hline Disease severity status on admission & & & & $0.696^{\mathrm{b}}$ \\
\hline Mild/moderate, n (\%) & $3(25.0)$ & $5(33.3)$ & & \\
\hline Severe, $\mathrm{n}(\%)$ & $9(75.0)$ & $10(66.7)$ & & \\
\hline \multicolumn{5}{|l|}{ Baseline laboratory parameters } \\
\hline Median WBC count, x10²/1 (IQR) & $5.4(4.2,8.5)$ & $6.9(6.2,11.3)$ & $\mathrm{t}=1.446$ & $0.161^{\mathrm{a}}$ \\
\hline Median lymphocytes, \% (IQR) & $19.3(8.8,25.1)$ & $10.9(6.9,22.1)$ & $\mathrm{t}=1.168$ & $0.254^{\mathrm{a}}$ \\
\hline Median CRP, mg/l (IQR) & $25.2(5.9,58.1)$ & $50.9(8.6,89.3)$ & $\mathrm{t}=0.189$ & $0.851^{\mathrm{a}}$ \\
\hline Transition to more severe cases, n (\%) & $1(8.3)$ & $7(46.7)$ & & $0.043^{\mathrm{b}}$ \\
\hline Oxygen therapy & & & & $1.000^{\mathrm{b}}$ \\
\hline Non-invasive ventilator support, $\mathrm{n}(\%)$ & $12(100.0)$ & $14(93.3)$ & & \\
\hline Ventilator support, $\mathrm{n}(\%)$ & $0(0.0)$ & $1(6.7)$ & & \\
\hline Clinical outcome & & & & $0.106^{\mathrm{b}}$ \\
\hline Discharged, n (\%) & $12(100.0)$ & $11(73.3)$ & & \\
\hline Death, n $(\%)$ & $0(0.0)$ & $4(26.7)$ & & \\
\hline
\end{tabular}

${ }^{a}$ Unpaired student's t-test; ${ }^{b}$ Fisher's exact test; ${ }^{c} \chi^{2}$ test. IQR, interquartile range; DM, diabetes mellitus; CCVD, cardio-cerebrovascular disease; COPD, chronic obstructive pulmonary disease; WBC, white blood cell; CRP, C-reactive protein.

broad-spectrum protease inhibitor, which has been shown to effectively inhibit a variety of cell proteolytic enzymes and have multifunctional therapeutic mechanisms (29). Firstly, ulinastatin has been shown to exert an inhibitory effect on the production of inflammatory cytokines and adhesion molecules (30). Moreover, ulinastatin may improve the stability of the lysosomal membrane, and reduce the synthesis and delivery of lysosomal enzymes, thus scavenging oxygen or hydroxyl radicals (15). In the present study, a beneficial effect of ulinastatin was observed on patients with Covid-19. Unfortunately, the present study did not investigate the changes in cytokines during treatment due to limitations of the hospital facility.

There were several limitations in the present study. Firstly, the number of patients enrolled was limited. Secondly, this was an observational and retrospective study, and other treatment factors may interfere with the outcomes. Previous studies revealed that systemic corticosteroids were frequently administered in patients with Covid-19 $(3,24)$ and corticosteroids treatment reduced the all-cause mortality (31). In the present study, five of 12 patients $(41.7 \%)$ in the ulinastatin treatment group and five of 15 patients $(33.3 \%)$ in the standard care group received systemic methylprednisolone treatment. The present preliminary results revealed the promising efficacy of ulinastatin for patients with Covid-19. Thus, further randomized controlled trials are warranted.
In conclusion, the present observational data revealed that administration of high-dose ulinastatin had a potential beneficial effect on patients with Covid-19. Considering the safety of this agent, the sharply rising number of fatalities due to Covid-19 and the absence of any other approved agent, timely initiation of ulinastatin treatment is strongly recommended.

\section{Acknowledgements}

Not applicable.

\section{Funding}

No funding was received.

\section{Availability of data and materials}

The datasets used and/or analyzed during the current study are available from the corresponding author on reasonable request.

\section{Authors' contributions}

HH, PFH, LLS, YBG and WFX analyzed and interpreted the data and had substantial contributions to conception and design of the work. QW, ZML, JZY, PMS and ZLY collected all the 
data from the patient's electronic medical records and analyzed the data. QW and PMS assessed the authenticity of all the raw data. All authors have read and approved the final manuscript.

\section{Ethics approval and consent to participate}

The present study was conducted in accordance with the Declaration of Helsinki (as revised in 2013). The present study was approved by the Ethics Committee of Shanghai Changzheng Hospital and Optical Valley Branch of Maternal and Child Hospital of Hubei Province, and individual consent for this retrospective analysis was waived.

\section{Patient consent for publication}

Not applicable.

\section{Competing interests}

The authors declare that they have no competing interests.

\section{References}

1. Guan WJ, Ni ZY, Hu Y, Liang WH, Ou CQ, He JX, Liu L, Shan H, Lei CL, Hui DSC, et al: Clinical characteristics of coronavirus disease 2019 in China. N Engl J Med 382: 1708-1720, 2020.

2. Cucinotta D and Vanelli M: WHO declares COVID-19 a pandemic. Acta Biomed 91: 157-160, 2020

3. Yang X, Yu Y, Xu J, Shu H, Xia J, Liu H, Wu Y, Zhang L, Yu Z, Fang M, et al: Clinical course and outcomes of critically ill patients with SARS-CoV-2 pneumonia in Wuhan, China: A single-centered, retrospective, observational study. Lancet Respir Med 8: 475-481, 2020.

4. Zhou YW, Xie Y, Tang LS, Pu D, Zhu YJ, Liu JY and Ma XL: Therapeutic targets and interventional strategies in COVID-19: Mechanisms and clinical studies. Signal Transduct Target Ther 6: 317, 2021.

5. Calina D, Docea AO, Petrakis D, Egorov AM, Ishmukhametov AA, Gabibov AG, Shtilman MI, Kostoff R, Carvalho F, Vinceti M, et al: Towards effective COVID-19 vaccines: Updates, perspectives and challenges (Review). Int J Mol Med 46: 3-16, 2020.

6. Nitulescu GM, Paunescu H, Moschos SA, Petrakis D, Nitulescu G, Ion GND, Spandidos DA, Nikolouzakis TK, Drakoulis N and Tsatsakis A: Comprehensive analysis of drugs to treat SARS-CoV-2 infection: Mechanistic insights into current COVID-19 therapies (Review). Int J Mol Med 46: 467-488, 2020

7. Chen G, Wu D, Guo W, Cao Y, Huang D, Wang H, Wang T, Zhang $\mathrm{X}$, Chen $\mathrm{H}, \mathrm{Yu} \mathrm{H}$, et al: Clinical and immunological features of severe and moderate coronavirus disease 2019. J Clin Invest 130: 2620-2629, 2020.

8. Cao X: COVID-19: Immunopathology and its implications for therapy. Nat Rev Immunol 20: 269-270, 2020.

9. Mehta P, Mcauley DF, Brown M, Sanchez E, Tattersall RS and Manson JJ; HLH Across Speciality Collaboration, UK: COVID-19: Consider cytokine storm syndromes and immunosuppression. Lancet 395: 1033-1034, 2020.

10. Yamamoto M,Matsuyama S,Li X, Takeda M,Kawaguchi Y,Inoue JI and Matsuda Z: Identification of nafamostat as a potent inhibitor of Middle East respiratory syndrome coronavirus S protein-mediated membrane fusion using the split-protein-based cell-cell fusion assay. Antimicro Agents Chemother 60: 6532-6539, 2016.

11. Hoffmann M, Kleine-Weber H, Schroeder S, Krüger N, Herrler T, Erichsen S, Schiergens TS, Herrler G, Wu NH, Nitsche A, et al: SARS-CoV-2 cell entry depends on ACE2 and TMPRSS 2 and is blocked by a clinically proven protease inhibitor. Cell 181: 271-280.e8, 2020.

12. Scudellari M: How the coronavirus infects cells-and why delta is so dangerous. Nature 595: 640-644, 2021.

13. Lagoo JY, D'souza MC, Kartha A and Kutappa AM: Role of ulinastatin, a trypsin inhibitor, in severe acute pancreatitis in critical care setting: A retrospective analysis. J Crit Care 45: 27-32, 2018.
14. Karnad DR, Bhadade R, Verma PK, Moulick ND, Daga MK, Chafekar ND and Iyer S: Intravenous administration of ulinastatin (human urinary trypsin inhibitor) in severe sepsis: A multicenter randomized controlled study. Intensive Care Med 40: 830-838, 2014

15. Ji M, Chen T, Wang B, Chen M, Ding Q, Chen L, Fang Y, Yu X, Chen Y, Wang X, et al: Effects of ulinastatin combined with mechanical ventilation on oxygen metabolism, inflammation and stress response and antioxidant capacity of ARDS. Exp Ther Med 15: 4665-4670, 2018

16. Zhang X, Zhu Z, Jiao W, Liu W, Liu F and Zhu X: Ulinastatin treatment for acute respiratory distress syndrome in China: A meta-analysis of randomized controlled trials. BMC Pulm Med 19: 196, 2019.

17. National Health Commission of China. Guideline for diagnosis and treatment for novel coronavirus pneumonia (seventh edition). http://www.nhc.gov.cn/yzygj/s7653p/202003/46c9294a7dfe4cef 80dc7f5912eb1989.shtml. Accessed March 4, 2020.

18. Sanders JM, Monogue ML, Jodlowski TZ and Cutrell JB: Pharmacologic treatments for coronavirus disease 2019 (COVID-19): A review. JAMA 323: 1824-1836, 2020.

19. Wang M, Cao R, Zhang L, Yang X, Liu J, Xu M, Shi Z, Hu Z, Zhong W and Xiao G: Remdesivir and chloroquine effectively inhibit the recently emerged novel coronavirus $(2019-\mathrm{nCoV})$ in vitro. Cell Res 30: 269-271, 2020.

20. Holshue ML, DeBolt C, Lindquist S, Lofy KH, Wiesman J, Bruce H, Spitters C, Ericson K, Wilkerson S, Tural A, et al: First case of 2019 novel coronavirus in the United States. N Engl J Med 382: 929-936, 2020.

21. Lescure FX, Bouadma L, Nguyen D, Parisey M, Wicky PH, Behillil S, Gaymard A, Bouscambert-Duchamp M, Donati F, Le Hingrat Q, et al: Clinical and virological data of the first cases of COVID-19 in Europe: A case series. Lancet Infect Dis 20: 697-706, 2020.

22. Grein J, Ohmagari N, Shin D, Diaz G, Asperges E, Castagna A, Feldt T, Green G, Green ML, Lescure FX, et al: Compassionate use of remdesivir for patients with severe Covid-19. N Engl J Med 382: 2327-2336, 2020.

23. Cao B, Wang Y, Wen D, Liu W, Wang J, Fan G, Ruan L, Song B, Cai Y, Wei M, et al: A trial of lopinavir-ritonavir in adults hospitalized with severe Covid-19. N Engl J Med 382: 1787-1799, 2020.

24. Zhou F, Yu T, Du R, Fan G, Liu Y, Liu Z, Xiang J, Wang Y, Song B, Gu X, et al: Clinical course and risk factors for mortality of adult inpatients with COVID-19 in Wuhan, China: A retrospective cohort study. Lancet 395: 1054-1062, 2020.

25. Guan WJ, Liang WH, Zhao Y, Liang HR, Chen ZS, Li YM, Liu XQ, Chen RC, Tang CL, Wang T, et al: Comorbidity and its impact on 1590 patients with Covid-19 in China: A nationwide analysis. Eur Respir J 55: 2000547, 2020.

26. Grasselli G, Zangrillo A, Zanella A, Antonelli M, Cabrini L, Castelli A, Cereda D, Coluccello A, Foti G, Fumagalli R, et al: Baseline characteristics and outcomes of 1591 patients infected with SARS-CoV-2 admitted to ICUs of the lombardy region, Italy. JAMA 323: 1574-1581, 2020.

27. Chen Q, Hu C, Liu Y, Liu Y, Wang W, Zheng H, Rong L, Jia J, Sun S, Yu C and Liu YM: Safety and tolerability of high-dose ulinastatin after 2-h intravenous infusion in adult healthy Chinese volunteers: A randomized, double-blind, placebo-controlled, ascending-dose study. PLoS One 12: e0177425, 2017.

28. World Health Organization. Clinical management of severe acute respiratory infection (SARI) when COVID-19 disease is suspected. Interim guidance. https://www.who. int/publications-detail/clinical-management-of-severe-acute-respiratoryinfection-when-novel-coronavirus-(ncov)-infection-is-suspected. Accessed March 13, 2020.

29. Linder A and Russell JA: An exciting candidate therapy for sepsis: Ulinastatin, a urinary protease inhibitor. Intensive Care Med 40: 1164-1167, 2014.

30. Kanai T, Ishiwata T, Kobayashi T, Sato H, Takizawa M, Kawamura Y, Tsujimoto H, Nakatani K, Ishibashi N, Nishiyama M, et al: Ulinastatin, a urinary trypsin inhibitor, for the initial treatment of patients with Kawasaki disease: A retrospective study. Circulation 124: 2822-2828, 2011.

31. Wagner C, Griesel M, Mikolajewska A, Mueller A, Nothacker M, Kley K, Metzendorf MI, Fischer AL, Kopp M, Stegemann M, et al: Systemic corticosteroids for the treatment of COVID-19. Cochrane Database Syst Rev 8: CD014963, 2021.

This work is licensed under a Creative Commons Attribution-NonCommercial-NoDerivatives 4.0 International (CC BY-NC-ND 4.0) License. 